\title{
Multi-Model Projections of Climate Change in Different RCP Scenarios in an Arid Inland Region, Northwest China
}

\author{
Ruotong Wang ${ }^{1,2}$, Qiuya Cheng ${ }^{1,2}$, Liu Liu ${ }^{1,2, * \mathbb{C}}$, Churui Yan ${ }^{1,2}$ and Guanhua Huang ${ }^{1,2,3}$ \\ 1 College of Water Resources and Civil Engineering, China Agricultural University, Beijing 100083, China; \\ hy96980308@cau.edu.cn (R.W.); qiuy77@126.com (Q.C.); sy20173091419@cau.edu.cn (C.Y.); \\ ghuang@cau.edu.cn (G.H.) \\ 2 Center for Agricultural Water Research in China, China Agricultural University, Beijing 100083, China \\ 3 Chinese-Israeli International Center for Research and Training in Agriculture, China Agricultural University, \\ Beijing 100083, China \\ * Correspondence: liuliu@cau.edu.cn; Tel.: +86-010-6273-6533
}

Received: 2 January 2019; Accepted: 14 February 2019; Published: 18 February 2019

\begin{abstract}
Based on three IPCC (Intergovernmental Panel on Climate Change) Representative Concentration Pathway (RCP) scenarios (RCP2.6, RCP4.5, and RCP8.5), observed meteorological data, ERA-40 reanalysis data, and five preferred GCM (general circulation model) outputs selected from 23 GCMs of CMIP5 (Phase 5 of the Coupled Model Intercomparison Project), climate change scenarios including daily precipitation, maximum air temperature, and minimum air temperature from 2021 to 2050 in the Heihe River basin, which is the second largest inland river basin in Northwest China, were generated by constructing a statistical downscaling model (SDSM). Results showed that the SDSM had a good prediction capacity for the air temperature in the Heihe River basin. During the calibration and validation periods from 1961 to 1990 and from 1991 to 2000, respectively, the coefficient of determination $\left(R^{2}\right)$ and the Nash-Sutcliffe efficiency coefficient (NSE) were both larger than 0.9 , while the root mean square error (RMSE) was within $20 \%$. However, the SDSM showed a relative lower simulation efficiency for precipitation, with $R^{2}$ and NSE values of most meteorological stations reaching 0.5 , except for stations located in the downstream desert areas. Compared with the baseline period (1976-2005), changes in the annual mean precipitation simulated by different GCMs during 2021-2050 showed great difference in the three RCP scenarios, fluctuating from -10 to $+10 \%$, which became much more significant at seasonal and monthly time scales, except for the consistent decreasing trend in summer and increasing trend in spring. However, the maximum and minimum air temperature exhibited a similar increasing tendency during 2021-2050 in all RCP scenarios, with a higher increase in maximum air temperature, which increased as the $\mathrm{CO}_{2}$ concentration of the RCP scenarios increased. The results could provide scientific reference for sustainable agricultural production and water resources management in arid inland areas subject to climate change.
\end{abstract}

Keywords: climate change; downscaling; ensemble projection; elevated $\mathrm{CO}_{2}$; uncertainty; Hexi Corridor

\section{Introduction}

China is one of the countries with the most significant impacts on climate change. The frequency and intensity of extreme climate events are increasing, and the regional features of climate are remarkable, while the impact of regional climate change on human life is more direct. Hence, research on the spatio-temporal characteristics of regional climate change and its impact adaptivity has become a key scientific issue to address the impact of global climate change at the regional level [1]. The Heihe River basin is located in the northwestern inland arid region of China and is one of the three 
rivers of the Hexi corridor, which has a very important strategic position. The midstream Zhangye is in the ancient "Silk Road" and the current Asia-Europe Continental Bridge, with a long history of agriculture and animal husbandry, which has become one of the top ten commodity grain bases in China; the Ejina Oasis in the downstream extends to the Delta zone of the Juyan Lake that is not only a natural barrier to protect the ecology but also an important support for the research and development of national defense and frontier construction [2]. However, due to the complex topography, arid climate, low vegetation coverage, and strong evaporation capacity in Northwest China, the vulnerability in this area is more significant in the face of climate change and other environmental fluctuations [3-5]. It has been shown [6-9] that since the late 1980s, climate change has exacerbated the instability of the hydro-meteorological system in Northwest China. The frequency and intensity of extreme hydrological-meteorological events have increased, which has caused serious adverse effects on local livelihood problems, such as agricultural production, water resources sustainable management, and food security, and has restricted the regional socio-economic development. Zhao et al. and Wang et al. $[10,11]$ pointed out that the change in extreme, high-temperature events in the Heihe River basin is consistent with the changes in extreme, high-temperature events in inland river basins of the Hexi Corridor and the northwestern region of China, while the trend of temperature increases is obviously surpassing the national overall level. Therefore, it is of great importance to find a reasonable and efficient way to project future climate change facing water-agriculture-ecology security in the Heihe River basin, which is also of remarkable theoretical and practical significance for the sustainable development of agriculture in the inland areas of Northwest China, and promoting the construction of "the Belt and Road."

General circulation models (GCMs) could provide global large-scale information for climate change research, but they have a relatively coarse spatial resolution; consequently, it is difficult to obtain climate change scenarios directly from outputs of GCMs, which agree well with the regional characteristics. It is also unreasonable to input directly the climate elements provided by GCMs into the responding models to estimate the impact of climate change on the river basin water cycle and surrounding environmental elements. To solve this issue, dynamical and statistical downscaling methods have been developed to convert larger-scale and lower-resolution GCMs outputs into higher-resolution climate variables at a regional scale [12-15]. In this study, the statistical downscaling model (SDSM) [16], which has been extensively used for the generation of climate change scenarios [17-22], was adopted. However, most previous studies have neglected adaptive assessment on GCM selection in terms of specific study areas. By comprehensively taking a GCM's initial conditions, downscaling techniques, hydrological model structures, and parameter uncertainties into consideration, Chen et al. [23] implied that uncertainties in climate change impact on water cycle mostly came from the GCM outputs, and significant differences among different GCMs were found. Elguindi et al. [24] applied the modified Thorthwaite climate classification to a 32-member ensemble of CMIP5 GCMs to evaluate model performance in both historical climate and projected future climate. The results showed that the multi-model ensemble reproduced the main spatial features of the global climate reasonably well; however, in many regions the climate types were too moist. Hence, multi-model ensemble projection without consideration of specific performance assessment is not appropriate to concisely depict the regional climate characteristics. To sum up, this study aims to (1) reduce the uncertainty of multi-model selection by assessing the GCMs adaptability, (2) construct the SDSM by ERA-40 reanalysis data and observed meteorological data based on multiple linear regression and a weather generator, and (3) provide the variation ranges of different climate variables simulated by multi-models in multiple scenarios to further eliminate the uncertainty based on a single GCM or GCM ensembles to project future climate change scenarios. Hence, the top five GCMs of the Heihe River basin were optimized based on sensitivity analysis of climate variables by the rank scoring method [25-27], which were adopted to generate future climate change scenarios by driving the SDSM in three Representative Concentration Pathway (RCP) scenarios (RCP2.6, RCP4.5, and RCP8.5), respectively, in the Heihe River basin, providing variation ranges of different climate variables. Results 
obtained in this study will provide a scientific reference for sustainable development of water security and agricultural production in arid inland regions subject to climate change.

\section{Materials and Methods}

\subsection{Study Area}

The Heihe River basin is the second largest inland river basin in China. It is located in the inland arid region of Northwest China, in the middle of the Hexi Corridor, roughly between $98-101^{\circ} 30^{\prime} \mathrm{E}$ and $38-42^{\circ} \mathrm{N}$. The total length is $821 \mathrm{~km}$ with a total area of $14.29 \times 10^{4} \mathrm{~km}^{2}$ and an annual runoff of $15.8 \times 10^{8} \mathrm{~m}^{3}$ [28]. Due to the complex terrain and landscape of the entire basin with significant altitude differences, a regional and zonal climate is extremely apparent. The Heihe River basin is divided by the Yingluo Gorge and the Zhengyi Gorge into the upper, middle, and lower reaches from south to north $[29,30]$. It is the upstream area of the Heihe River basin from the Qilian Mountains to the Yingluo Gorge, which is the mountainous area producing main runoff with an altitude between 1680 and $5280 \mathrm{~m}$. It is a cold and humid climate zone with an annual average temperature of $2-3^{\circ} \mathrm{C}$, and the average annual precipitation is $200-500 \mathrm{~mm}$ [31]. The midstream is between the Yingluo Gorge and the Zhengyi Gorge. The terrain is a mix of mountains and plains with an altitude between 1300 and $1680 \mathrm{~m}$. The average annual temperature and precipitation is $6-8^{\circ} \mathrm{C}$ and $120-200 \mathrm{~mm}$, respectively [31]. The midstream is the agricultural production base of the Heihe River basin due to abundant light and heat resources, which concentrates more than $90 \%$ of the population and cultivated land in the whole basin. However, according to historical records, the total amount of precipitation during the crop growth period of the arid year is much lower than that of the non-arid year in the midstream, causing substantial reduction of agriculture and animal husbandry production. Below the Zhengyi Gorge is the downstream, with an altitude from 980 to $1300 \mathrm{~m}$, characterized by the vast Gobi desert where the runoff is greatly reduced or disappears through evaporation and where river leakage with the average annual temperature and precipitation is $8-10^{\circ} \mathrm{C}$ and less than $50 \mathrm{~mm}$, respectively [29-31].

\subsection{Data}

(1) Observed meteorological data. In this study, the measured meteorological data, including daily precipitation, mean air temperature, maximum air temperature, and minimum air temperature from 17 meteorological stations evenly distributed in the Heihe River basin (as shown in Figure 1) during 1961-2000 were obtained from China Meteorological Data Service Center (http:/ / data.cma.cn/). The monthly meteorological data from 1961 to 2000 were organized and generated for GCM rank scoring, while the daily data from 1961 to 1990 were used for SDSM calibration, and the daily data from 1991 to 2000 were used for model validation. 


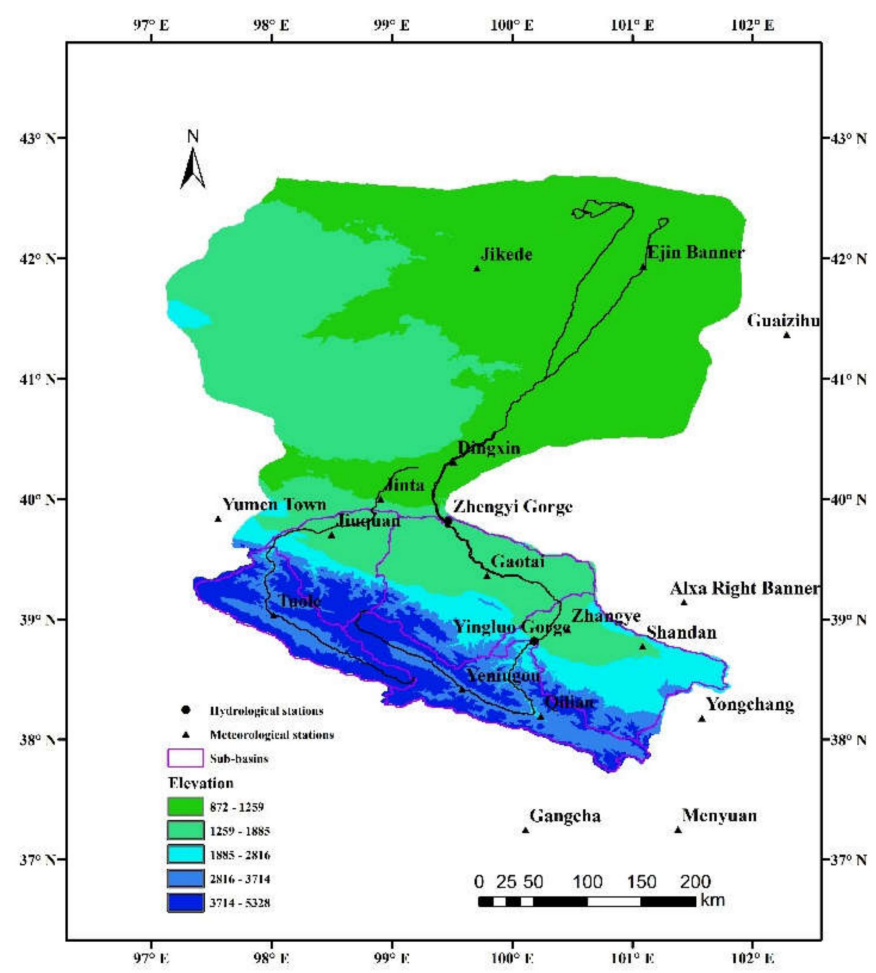

Figure 1. Location of the Heihe River basin and hydro-meteorological stations.

(2) ERA-40 reanalysis data. Compared with other reanalysis data, the second generation 40-year reanalysis data (ERA-40) of the European Centre for Medium-Range Weather Forecasts (ECMWF) have been proven by many studies [32-34] to be appropriate for characterizing the temporal and spatial patterns of meteorological elements such as surface precipitation and air temperature and pressure in most parts of China, especially in Western China. In this study, we downloaded and reproduced the daily ERA-40 reanalysis data during 1961-2000 from the ECMWF (http:/ / apps.ecmwf.int/datasets / data /era40-daily /levtype $=\mathrm{sfc} /$ ) at a spatial resolution of $2^{\circ} \times 2^{\circ}$.

(3) GCMs data, both monthly and daily, were obtained from the Phase 5 of the Coupled Model Intercomparison Project (CMIP5) archive (http:// cmip-pcmdi.llnl.gov/cmip5/) supplied by CEDA (Centre for Environmental Data Analysis). The selection of 23 GCMs is due to the number of available predictors and the length of the time series. The monthly data from 1961 to 2000 were used for GCM performance evaluation and were uniformly interpolated to a $2^{\circ} \times 2^{\circ}$ spatial resolution, corresponding to the spatial resolution of ERA-40. The daily data were used for statistical downscaling to generate climate change scenarios of the baseline period (1976-2005) and the future period (2018-2047) in three RCP scenarios (RCP2.6, RCP4.5, and RCP8.5). The RCPs are named according to the radiative forcing target level for 2100 . RCP2.6 is defined as a peak in radiative forcing at $3 \mathrm{~W} / \mathrm{m}^{2}$ before 2100 that declines to $2.6 \mathrm{~W} / \mathrm{m}^{2}$ (around $490 \mathrm{ppm} \mathrm{CO}$ equiv) by 2100. The definitions of the RCP4.5 and RCP 8.5 are described as stabilization without an overshoot pathway to $4.5 \mathrm{~W} / \mathrm{m}^{2}$ (around $650 \mathrm{ppm} \mathrm{CO}_{2}$ equiv) after 2100 and as a rising radiative forcing pathway leading to $8.5 \mathrm{~W} / \mathrm{m}^{2}$ (around $1370 \mathrm{ppm}$ $\mathrm{CO}_{2}$ equiv) by 2100 [35]. The selected 23 GCMs and their detailed information are shown in Table 1.

Table 1. Information of selected 23 general circulation models (GCMs) from Phase 5 of the Coupled Model Intercomparison Project (CMIP5).

\begin{tabular}{cccc}
\hline GCM & Model & Source & Spatial Resolution \\
\hline 1 & BCC-CSM 1-1 & Beijing Climate Center, China Meteorological Administration, China & $2.7906^{\circ} \times 2.8125^{\circ}$ \\
2 & BCC-CSM1-1-M & Beijing Climate Center, China Meteorological Administration, China & $1.125^{\circ} \times 1.125^{\circ}$ \\
3 & BNU-ESM & Beijing Normal University, China & $2.7906^{\circ} \times 2.8125^{\circ}$ \\
4 & CanESM2 & Canadian Centre for Climate Modelling and Analysis, Canada & $2.7906^{\circ} \times 2.8125^{\circ}$ \\
\hline
\end{tabular}


Table 1. Cont.

\begin{tabular}{|c|c|c|c|}
\hline GCM & Model & Source & Spatial Resolution \\
\hline 5 & CCSM4 & National Center for Atmospheric Research (NCAR), USA & $0.9424^{\circ} \times 1.25^{\circ}$ \\
\hline 6 & CNRM-CM5 & Centre National de Recherches Meteorologiques, Meteo-France, France & $1.4005^{\circ} \times 1.4065^{\circ}$ \\
\hline 7 & CSIRO-Mk3.6.0 & $\begin{array}{c}\text { Australian Commonwealth Scientific and Industrial Research } \\
\text { Organization, Australia }\end{array}$ & $1.8653^{\circ} \times 1.875^{\circ}$ \\
\hline 8 & FGOALS-g2 & Institute of Atmospheric Physics, Chinese Academy of Sciences, China & $2.7906^{\circ} \times 2.8125^{\circ}$ \\
\hline 9 & FIO-ESM & The First Institute of Oceanography, SOA, China & $2.7906^{\circ} \times 2.8125^{\circ}$ \\
\hline 10 & GFDL-CM3 & Geophysical Fluid Dynamics Laboratory, USA & $2^{\circ} \times 2.5^{\circ}$ \\
\hline 11 & GFDL-ESM2G & Geophysical Fluid Dynamics Laboratory, USA & $2^{\circ} \times 2.5^{\circ}$ \\
\hline 12 & GISS-E2-H & NASA Goddard Institute for Space Studies, USA & $2^{\circ} \times 2.5^{\circ}$ \\
\hline 13 & GISS-E2-R & NASA Goddard Institute for Space Studies, USA & $2^{\circ} \times 2.5^{\circ}$ \\
\hline 14 & HadGEM2-ES & Met Office Hadley Centre, UK & $1.25^{\circ} \times 1.875^{\circ}$ \\
\hline 15 & IPSL-CM5A-LR & Institut Pierre-Simon Laplace, France & $1.8947^{\circ} \times 3.75^{\circ}$ \\
\hline 16 & IPSL-CM5A-MR & Institut Pierre-Simon Laplace, France & $1.2676^{\circ} \times 2.5^{\circ}$ \\
\hline 17 & MIROC5 & $\begin{array}{c}\text { Atmosphere and Ocean Research Institute (The University of Tokyo), } \\
\text { National Institute for Environmental Studies, and Japan Agency for } \\
\text { Marine-Earth Science and Technology, Japan }\end{array}$ & $1.4005^{\circ} \times 1.4065^{\circ}$ \\
\hline 18 & MIROC-ESM & $\begin{array}{l}\text { Atmosphere and Ocean Research Institute (The University of Tokyo), } \\
\text { National Institute for Environmental Studies, and Japan Agency for } \\
\text { Marine-Earth Science and Technology, Japan }\end{array}$ & $2.7906^{\circ} \times 2.8125^{\circ}$ \\
\hline 19 & MIROC-ESM-CHEM & $\begin{array}{c}\text { Atmosphere and Ocean Research Institute (The University of Tokyo), } \\
\text { National Institute for Environmental Studies, and Japan Agency for } \\
\text { Marine-Earth Science and Technology, Japan }\end{array}$ & $2.7906^{\circ} \times 2.8125^{\circ}$ \\
\hline 20 & MPI-ESM-LR & Max Planck Institute for Meteorology, Germany & $1.8653^{\circ} \times 1.875^{\circ}$ \\
\hline 21 & MPI-ESM-MR & Max Planck Institute for Meteorology, Germamy & $1.8653^{\circ} \times 1.875^{\circ}$ \\
\hline 22 & MRI-CGCM3 & Meteorological Research Institute, Japan & $2.2145^{\circ} \times 1.125^{\circ}$ \\
\hline 23 & NorESM1-M & Norwegian Climate Centre, Norway & $1.8947^{\circ} \times 2.5^{\circ}$ \\
\hline
\end{tabular}

Note: Five GCMs in bold here are highlighted as the top 5 GCMs selected for climate change projections.

\subsection{Methods}

\subsubsection{Multi-Model Adaptive Assessment}

The GCM is currently the most feasible method for predicting large-scale climate changes. However, due to the differences in resolution, initial conditions, and mechanisms of each GCM, the results have significant uncertainty, and the accuracy of the simulated results is closely related to the simulated region and the simulated climate variables [36-40]. Therefore, it is necessary to conduct an adaptive assessment of each GCM in the study area before using GCM data to investigate regional climate change, and then to select the GCMs with better regional adaptability.

The score-based method was proposed to assess the performance of the GCMs in simulating precipitation and temperature, which has already been applied in research of multiple regions for GCM adaptive assessment $[25,41,42]$. A multi-criteria rank score $(R S)$ value was computed for each individual assessment criterion as

$$
R S_{i}=\frac{X_{\max }-X_{i}}{X_{\max }-X_{\min }} \times 10
$$

where $X_{i}$ is the relative error or relationship statistic between the GCM output and observed for the $i$ th GCM. High RS values indicate high GCM performance. The total $R S$ for each GCM for a specific climate variable was obtained by summing all $R S$ for all criteria used. All assessment criteria used have a 1.0 weight in this summation except for trend analysis, trend magnitude, the first two leading modes of each EOF (EOF1 and EOF2), and two PDF criteria (BS and Score), which are each weighted as 0.5 . This total $R S$ was then used to rank the GCMs for all climate variables. Eleven statistics used in this study are shown in Table 2. 
Table 2. Statistics of climate variables used for GCM performance assessment.

\begin{tabular}{cc}
\hline Statistics of Climate Variables & Methods \\
\hline Mean & Relative Error $(\%)$ \\
Standard deviation & Relative Error $(\%)$ \\
Temporal variation & NRMSE \\
Monthly distribution(Annual cycle) & Correlation Coefficient \\
Spatial distribution & Correlation Coefficient \\
Trend and its magnitude & Mann-Kendall test $Z$ \\
& Mann-Kendall test $\beta$ \\
Space-time variability & EOF1 \\
& EOF2 \\
Probability density functions (PDFs) & $B S$ \\
& $S_{\text {score }}$ \\
\hline
\end{tabular}

In this study, GCM evaluation was implemented based on observed monthly precipitation and air temperatures (mean, maximum, minimum) from 1961 to 2000 at 17 meteorological stations, and on the corresponding simulated monthly data from 23 GCMs for the same period. Furthermore, the selection of climate variables and statistical criteria in the score-based method is of great importance for the final $R S$ values. Compared with the impact of statistical criteria, the impact of climate variables on $R S$ values are much more direct and significant. Hence, in order to better select the GCMs suitable for the Heihe River basin, quantitative sensitivity analyses of $R S$ values on different climate variables were conducted to improve the credibility of the GCMs' adaptive assessment.

\subsubsection{The Statistical Downscaling Model}

The SDSM is a statistical downscaling model based on the principle of coupling between the weather generator and multiple linear regression. It is easy to operate, has been widely used in the downscaling of regional climate changes, and overcomes the weakness of using only one method to estimate future climate change [43]. An SDSM [44] screens the predictors closely related to the predictands and builds an empirical statistical relationship between the predictands (climate variables of the observed meteorological stations) and the predictors (ERA-40 reanalysis data) based on multiple linear regression. An empirical relationship is applied to the weather generator, and the SDSM is driven by GCM outputs to generate the future daily series of station climate elements [45]. In summary, the SDSM assumes stable statistical relationships; that is, the empirical statistical relationship is constant in the case of future changes in climatic conditions.

The relationship between the predictands and predictors is expressed as

$$
R=F(L)
$$

where $R$ represents the predictands, $L$ represents the predictors, and $F$ represents the deterministic or random function.

Screening downscaling predictors is key to the SDSM, and largely determines the results of downscaling and future climate scenarios [16]. In the SDSM, the selection of predictors is an iterative process, based on the results of seasonal correlation analysis, partial correlation analysis, and scatter plots. Furthermore, seasonal correlation analysis is conducted by investigating the percentage of variance explained by specific predictand-predictor pairs and by judiciously concerning the most appropriate combination of predictors for a given season and predictand. Partial correlation analysis was used to investigate inter-variable correlations. These statistics help to identify the amount of explanatory power that is unique to each predictor. Drawing the scatter plot was used for exhibiting the relationship between a single predictor and the predictand. The resultant scatterplot indicates the nature of the association, whether or not data transformation may be needed, and the importance of outliers $[46,47]$. 
The empirical statistical relationship between predictands and selected predictors were established by the SDSM, that is, model calibration [43]. During the calibration process, the model structure needs to be determined. "Conditional" vs. "unconditional" is chosen by judging whether there is a direct physical connection between the predictands and predictors. In this study, calibration processes of temperature and precipitation were determined as unconditional and conditional processes, respectively [16]. Daily precipitation amounts depend on an intermediate variable such as the probability of wet-day occurrence. The SDSM is calibrated by artificially inflating the variance inflation (VIF) and bias correction (BC) of downscaled series based on their change ranges to accord better with daily observations. Furthermore, $0<\mathrm{VIF}<10$ indicates no correlation; $10<\mathrm{VIF}<100$ indicates a moderate correlation; VIF $\geq 100$ indicates a high correlation. The VIF default value is 12 . The value of $\mathrm{BC}$ ranges from 0 to 2 . The $\mathrm{BC}$ default value is 1.0, which indicates no bias correction [44,47].

In this study, the coefficient of determination $\left(R^{2}\right)$, the root mean square error (RMSE), and the Nash-Sutcliffe efficiency coefficient (NSE) were used to evaluate the effect of model calibration and validation, which can be expressed as follows:

$$
\begin{gathered}
R^{2}=\frac{\left[\sum_{\mathrm{i}=1}^{N}\left(O_{i}-\bar{O}\right)\left(P_{i}-\bar{P}\right)\right]^{2}}{\sum_{\mathrm{i}=1}^{N}\left(O_{i}-\bar{O}\right)^{2} \sum_{\mathrm{i}=1}^{N}\left(P_{i}-\bar{P}\right)^{2}} \\
R M S E=\sqrt{\frac{\sum_{\mathrm{i}=1}^{N}\left(O_{i}-P_{i}\right)^{2}}{N}} \\
N S E=1-\frac{\sum_{\mathrm{i}=1}^{N}\left(O_{i}-P_{i}\right)^{2}}{\sum_{\mathrm{i}=1}^{N}\left(O_{i}-\bar{O}\right)^{2}}
\end{gathered}
$$

where $N$ is the length of time, $O_{i}$ is the observed value, $P_{i}$ is the simulated value, and $\bar{O}$ is the mean of the observed values.

The future climate change scenarios of each meteorological station generated by the validated SDSM were then interpolated to the whole Heihe River basin to identify the temporal variation characteristics at different time scales and spatial changing patterns in the upper, middle, and lower reaches of this basin.

\section{Results and Discussion}

\subsection{CMIP5 Multi-Model Adaptive Assessment}

\subsubsection{Rank Scoring of Different Climate Variables}

Figure 2 shows the evaluation results of the 23 GCMs, indicating their influences on the precipitation, mean air temperature, maximum air temperature, and minimum air temperature. The GCMs with the best simulation effects for the above four climate variables were CNRM-CM5 (7.15), CCSM4 (8.55), MPI-ESM-LR (6.94), and BCC-CSM1-1-M (8.75), respectively. Compared with the significant differences of the precipitation simulation effects from the $23 \mathrm{GCMs}$, the $R S$ values of all the GCMs were above 5.0 in terms of mean air temperature simulation, implying good simulation effects, while the $R S$ values of the maximum air temperature and the minimum air temperature ranged from 3.43 to 6.33 and from 3.32 to 6.93 , respectively. 


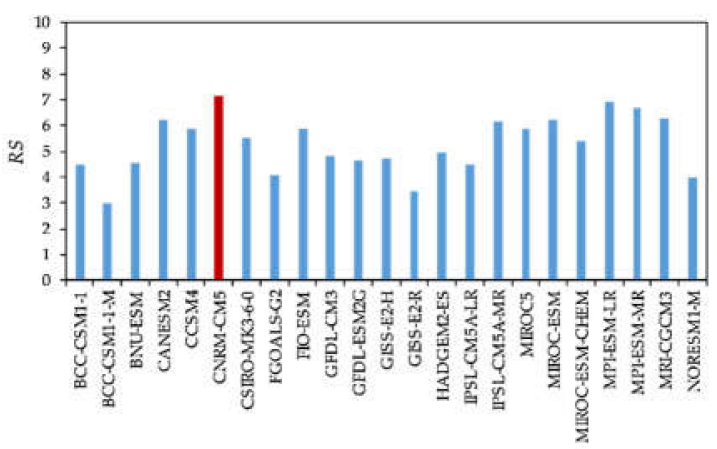

(a)

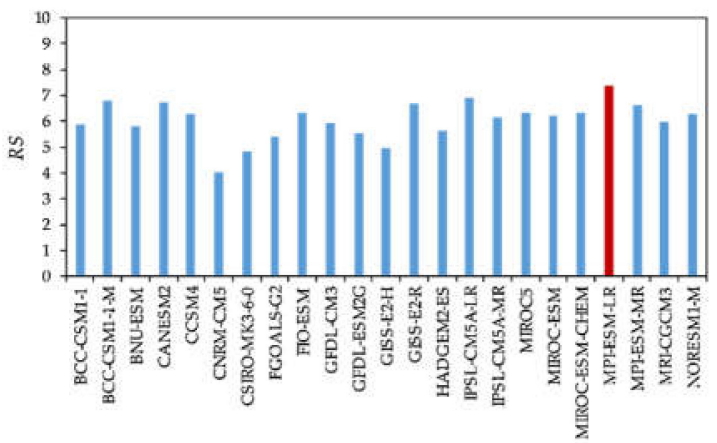

(c)

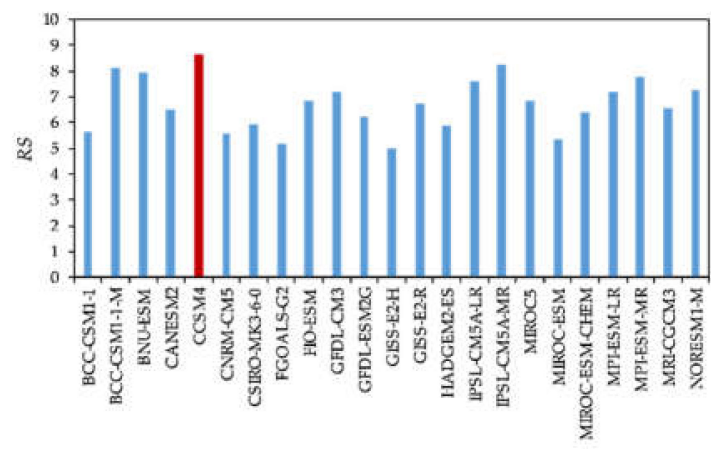

(b)

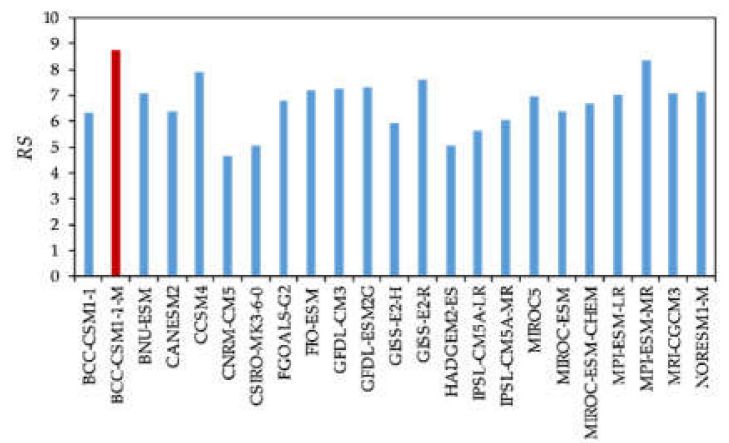

(d)

Figure 2. Results of performance evaluation from 23 GCMs by the score-based method for (a) precipitation; (b) mean air temperature; (c) maximum air temperature; and (d) minimum air temperature.

\subsubsection{Sensitivity Analysis on Score-Based Evaluation Results}

As shown in Figure 3, selection of climate variables has a significant impact on the rank score results. For example, the RS value of BCC-CSM1-1-M is 6.66 when taking precipitation into consideration, while the $R S$ value comes up to 7.89 without consideration of precipitation, causing the score ranking of the model to increase from 4 th to 1st. Therefore, it is necessary to identify suitable climate variables to evaluate GCM performance with respect to specific river basins for particular research purposes, making the simulated results more accurate and convincing. According to the sensitivity analysis results shown in Figure 3, RS value was most sensitive to precipitation in the Heihe River basin, so the top five GCMs exhibiting the best performance of precipitation were selected to use the SDSM to generate future climate change scenarios, and these GCMs were CNRM-CM5, MPI-ESM-LR, MPI-ESM-MR, MRI-CGCM3, and CANESM2.

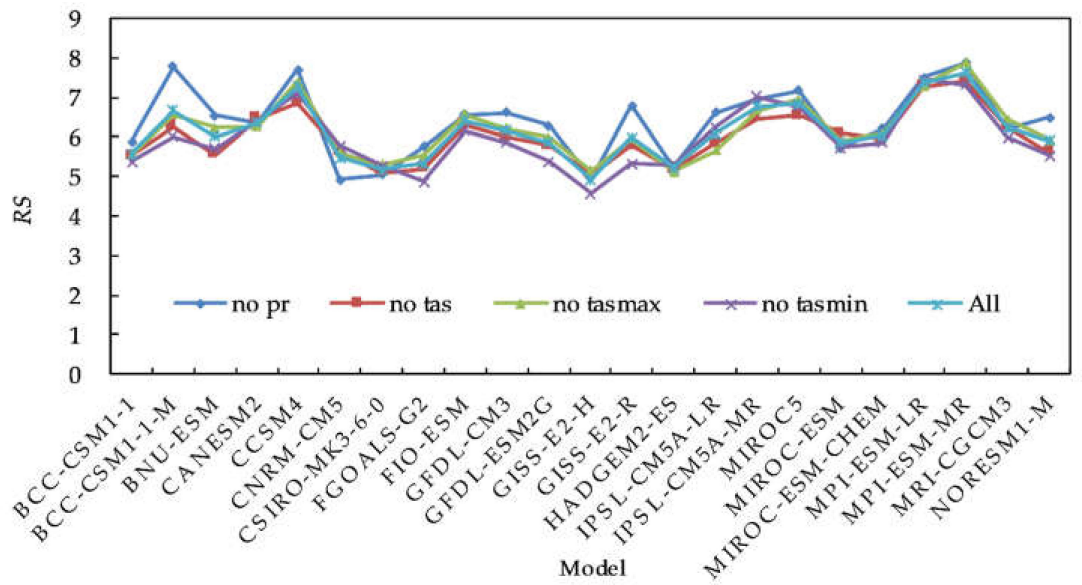

Figure 3. Sensitivity analysis for climate variables. 


\subsection{Projection of Future Climate Change}

\subsubsection{Screen Predictors}

Ideally, candidate predictor variables should be physically and conceptually sensible with respect to the predictand, readily available from archives of ERA-40 reanalysis data and GCM output, and accurately modeled by GCMs [45]. Additionally, seasonal correlation analysis, partial correlation analysis, and scatter plots of the SDSM were used to analyze the daily observation data measured at the meteorological stations and the ERA-40 reanalysis data to screen and select the predictors needed for the various climate variables corresponding to the specific 17 meteorological stations surrounding the Heihe River basin and to assure that the predictors strongly and consistently physically correlated with the predictands. Table 3 shows the predictors of precipitation, mean air temperature, maximum air temperature, and minimum air temperature selected for each station, respectively. For detailed descriptions of the selected predictors, refer to Guo et al. [48] and Fan et al. [49].

Table 3. Selected predictors according to different predictands of the 17 meteorological stations.

\begin{tabular}{|c|c|c|c|c|}
\hline Stations & $\mathrm{T}_{\max }$ & $\mathbf{T}_{\min }$ & $\mathrm{T}_{\text {mean }}$ & Precipitation \\
\hline Jikede & $\begin{array}{c}\text { mslp, p5ta, } \\
\text { p7ta, p8ta, ta2m }\end{array}$ & $\begin{array}{l}\text { mslp, p5ta, p7ta, p8ta, } \\
\text { ta2m, p7hu, p8hu }\end{array}$ & $\begin{array}{l}\text { mslp, p5ta, p7ta, } \\
\text { p8ta, ta } 2 \mathrm{~m}\end{array}$ & $\begin{array}{l}\text { lspr, mslp, p7ta, p8ta, } \\
\text { ta } 2 \mathrm{~m}, \mathrm{p} 7 \mathrm{hu}, \mathrm{p} 8 \mathrm{hu}\end{array}$ \\
\hline Ejin Banner & $\begin{array}{l}\text { mslp, p7ta, } \\
\text { p8ta, ta2m }\end{array}$ & $\begin{array}{l}\text { mslp, p5ta, p7ta, p8ta, } \\
\text { ta } 2 \text { m, p7hu, p8hu }\end{array}$ & $\begin{array}{l}\text { mslp, p5ta, p7ta, } \\
\text { p8ta, ta2m }\end{array}$ & $\begin{array}{l}\text { lspr, p7ta, p8ta, ta2m, } \\
\text { p5hu, p7hu, p8hu }\end{array}$ \\
\hline Guaizihu & $\begin{array}{l}\text { mslp, p7ta, } \\
\text { p8ta, ta2m }\end{array}$ & $\begin{array}{c}\text { mslp, p5ta, p7ta, } \\
\text { p8ta, ta2m }\end{array}$ & $\begin{array}{l}\text { mslp, p7ta, } \\
\text { p8ta, ta2m }\end{array}$ & $\begin{array}{l}\text { lspr, p7ta, p8ta, ta2m, } \\
\text { p5hu, p7hu, p8hu }\end{array}$ \\
\hline Yumen Town & $\begin{array}{l}\text { mslp, p7ta, } \\
\text { p8ta, ta2m }\end{array}$ & $\begin{array}{c}\text { mslp, p5ta, p7ta, p8ta, } \\
\text { ta2m, p7hu }\end{array}$ & $\begin{array}{l}\text { mslp, p7ta, } \\
\text { p8ta, ta2m }\end{array}$ & $\begin{array}{l}\text { lspr, mslp, p7ta, p8ta, } \\
\text { ta2m, p7hu, p8hu }\end{array}$ \\
\hline Jiuquan & $\begin{array}{l}\text { mslp, p7ta, } \\
\text { p8ta, ta2m }\end{array}$ & $\begin{array}{c}\text { mslp, p5ta, p7ta, p8ta, } \\
\text { ta2m, p7hu }\end{array}$ & $\begin{array}{l}\text { mslp, p7ta, } \\
\text { p8ta, ta2m }\end{array}$ & $\begin{array}{l}\text { lspr, mslp, p7ta, p8ta, } \\
\text { ta2m, p7hu, p8hu }\end{array}$ \\
\hline Jinta & $\begin{array}{l}\text { mslp, p7ta, } \\
\text { p8ta, ta2m }\end{array}$ & $\begin{array}{l}\text { mslp, p5ta, p7ta, p8ta, } \\
\text { ta } 2 \mathrm{~m}, \mathrm{p} 7 \mathrm{hu}, \mathrm{p} 8 \mathrm{hu}\end{array}$ & $\begin{array}{l}\text { mslp, p7ta, } \\
\text { p8ta, ta2m }\end{array}$ & $\begin{array}{l}\text { lspr, mslp, p7ta, p8ta, } \\
\text { ta2m, p7hu, p8hu }\end{array}$ \\
\hline Dingxin & $\begin{array}{l}\text { mslp, p7ta, } \\
\text { p8ta, ta2m }\end{array}$ & $\begin{array}{l}\text { mslp, p5ta, p7ta, p8ta, } \\
\text { ta } 2 \mathrm{~m}, \mathrm{p} 7 \mathrm{hu}, \mathrm{p} 8 \mathrm{hu}\end{array}$ & $\begin{array}{l}\text { mslp, p7ta, } \\
\text { p8ta, ta2m }\end{array}$ & $\begin{array}{l}\text { lspr, mslp, p7ta, p8ta, } \\
\text { ta2m, p7hu, p8hu }\end{array}$ \\
\hline Gaotai & $\begin{array}{l}\text { mslp, p7ta, } \\
\text { p8ta, ta2m }\end{array}$ & $\begin{array}{l}\text { p5ta, p8ta, ta2m, } \\
\text { p7hu, p8hu }\end{array}$ & $\begin{array}{l}\text { mslp, p7ta, } \\
\text { p8ta, ta2m }\end{array}$ & $\begin{array}{l}\text { lspr, mslp, p7ta, p8ta, } \\
\text { ta2m, p7hu, p8hu }\end{array}$ \\
\hline Alxa Right Banner & $\begin{array}{l}\text { mslp, p7ta, } \\
\text { p8ta, ta2m }\end{array}$ & $\begin{array}{l}\text { mslp, p5ta, p7ta, } \\
\text { p8ta, ta2m }\end{array}$ & $\begin{array}{l}\text { mslp, p7ta, } \\
\text { p8ta, ta2m }\end{array}$ & $\begin{array}{l}\text { lspr, mslp, p7ta, p8ta, } \\
\text { ta2m, p7hu, p8hu }\end{array}$ \\
\hline Tuole & $\begin{array}{c}\text { mslp, p5ta, } \\
\text { p7ta, p8ta, ta2m }\end{array}$ & p5ta, ta2m, p8hu & $\begin{array}{l}\text { p5ta, p7ta, } \\
\text { p8ta, ta2m }\end{array}$ & $\begin{array}{l}\text { lspr, mslp, p7ta, p8ta, } \\
\text { ta2m, p8hu }\end{array}$ \\
\hline Yeniugou & $\begin{array}{c}\text { mslp, p5ta, } \\
\text { p7ta, p8ta, ta2m }\end{array}$ & $\begin{array}{l}\text { p5ta, ta2m, p5hu, } \\
\text { p7hu, p8hu }\end{array}$ & $\begin{array}{l}\text { p5ta, p7ta, } \\
\text { p8ta, ta2m }\end{array}$ & $\begin{array}{l}\text { lspr, mslp, p7ta, p8ta, } \\
\text { ta2m, p7hu, p8hu }\end{array}$ \\
\hline Zhangye & $\begin{array}{l}\text { mslp, p7ta, } \\
\text { p8ta, ta2m }\end{array}$ & $\begin{array}{l}\text { p5ta, ta2m, p5hu, } \\
\text { p7hu, p8hu }\end{array}$ & $\begin{array}{l}\text { mslp, p5ta, p7ta, } \\
\text { p8ta, ta2m }\end{array}$ & $\begin{array}{l}\text { lspr, mslp, p7ta, p8ta, } \\
\text { ta2m, p7hu, p8hu }\end{array}$ \\
\hline Qilian & $\begin{array}{c}\text { mslp, p5ta, } \\
\text { p7ta, p8ta, ta2m }\end{array}$ & $\begin{array}{l}\text { ta2m, p5hu, } \\
\text { p7hu, p8hu }\end{array}$ & $\begin{array}{l}\text { mslp, p5ta, p7ta, } \\
\text { p8ta, ta2m }\end{array}$ & $\begin{array}{l}\text { lspr, mslp, p7ta, p8ta, } \\
\text { ta2m, p7hu, p8hu }\end{array}$ \\
\hline Gangcha & $\begin{array}{c}\text { mslp, p5ta, } \\
\text { p7ta, p8ta, ta2m }\end{array}$ & $\begin{array}{l}\text { p5ta, ta2m, p5hu, } \\
\text { p7hu, p8hu }\end{array}$ & $\begin{array}{l}\text { p5ta, p7ta, } \\
\text { p8ta, ta2m }\end{array}$ & $\begin{array}{l}\text { lspr, mslp, p7ta, p8ta, } \\
\text { ta2m, p7hu, p8hu }\end{array}$ \\
\hline Shandan & $\begin{array}{l}\text { mslp, p7ta, } \\
\text { p8ta, ta2m }\end{array}$ & $\begin{array}{l}\text { p5ta, p8ta, ta2m, p5hu, } \\
\text { p7hu, p8hu }\end{array}$ & $\begin{array}{c}\text { mslp, p5ta, } \\
\text { p7ta, p8ta, ta2m }\end{array}$ & $\begin{array}{l}\text { lspr, mslp, p7ta, p8ta, } \\
\text { ta2m, p7hu, p8hu }\end{array}$ \\
\hline Yongchang & $\begin{array}{l}\text { mslp, p7ta, } \\
\text { p8ta, ta2m }\end{array}$ & $\begin{array}{l}\text { p5ta, p8ta, ta2m, p5hu, } \\
\text { p7hu, p8hu }\end{array}$ & $\begin{array}{l}\text { mslp, p7ta, } \\
\text { p8ta, ta2m }\end{array}$ & $\begin{array}{l}\text { lspr, mslp, p7ta, p8ta, } \\
\text { ta2m, p7hu, p8hu }\end{array}$ \\
\hline Menyuan & $\begin{array}{c}\text { mslp, p5ta, } \\
\text { p7ta, p8ta, ta2m }\end{array}$ & $\begin{array}{c}\text { p5ta, ta2m, p5hu, } \\
\text { p7hu, p8hu }\end{array}$ & $\begin{array}{l}\text { mslp, p5ta, p7ta, } \\
\text { p8ta, ta2m }\end{array}$ & $\begin{array}{l}\text { lspr, mslp, p7ta, p8ta, } \\
\text { ta2m, p7hu, p8hu }\end{array}$ \\
\hline
\end{tabular}

\subsubsection{SDSM Calibration and Validation}

In this study, the period from 1961 to 1990 was selected as the calibration period, while the period from 1991 to 2000 was used as the validation period. The optimal empirical statistical relationships of each station were established between predictands and selected predictors by adjusting the two parameters of VIF and BC [47]. As shown in Table 4, the $R^{2}$ values of the mean air temperature from the 17 meteorological stations surrounding the Heihe River basin during the calibration period (1961-1990) and validation period (1991-2000) were 0.954-0.983 and 0.957-0.987, respectively, 
indicating a significant correlation between the simulated and measured values. The RMSE during the calibration period and validation period were $1.61-2.22{ }^{\circ} \mathrm{C}$ and $1.585-2.259^{\circ} \mathrm{C}$, respectively, most of which were within $20 \%$ of the measured values (Table 5). The NSE values of the mean air temperature during both the calibration period and validation period were all greater than 0.96 (Table 6), implying that the simulation effect of this model was outstanding. To sum up, the SDSM was effective in simulating the mean air temperature for the meteorological stations surrounding the Heihe River basin, and could therefore be used for the projections of the mean air temperature in the next step.

Likewise, $R^{2}$ values of the maximum air temperature and the minimum air temperature for each station during the calibration period and validation period were mostly above 0.9 , indicating a good correlation between the simulated value and the measured value. During the calibration period and validation period, the RMSE of the maximum air temperature for most stations was smaller than $2{ }^{\circ} \mathrm{C}$, while that of the minimum air temperature was within $3{ }^{\circ} \mathrm{C}$, implying a better simulation effect of the maximum air temperature than that of the minimum air temperature. However, both of their NSEs were greater than 0.9 , indicating that the model had good simulation efficiency. Due to the excellent simulation effect on the maximum air temperature and good simulation effect on the minimum air temperature, the SDSM could be used to downscale the maximum and minimum air temperature from GCM outputs.

The $R^{2}$ values of precipitation during the calibration period and validation period, compared with those of the air temperature, were slightly lower, especially in the lower reaches of the desert region, including Ejin Banner, Jikede, and Guaizihu, with values of $R^{2}$ lower than 0.5. Precipitation is not only affected by atmospheric circulation factors but also by the underlying surface conditions and human activities, and thus is difficult to accurately simulate with the SDSM [50]. Furthermore, the arid region of Northwest China is one of the areas in the world that responds most sensitively to global climate change [5], where its climate change is complex and diverse. Qi et al. [51] and Hao et al. [52] both pointed out that the $R^{2}$ values of precipitation in the upper and middle reaches centered around Zhangye and Gaotai stations were all less than 0.5. In this study, the empirical statistical relationships between predictands and predictors were set to the optimal condition, deriving larger $R^{2}$ values $(>0.5)$ for all meteorological stations located in the upper and middle reaches, and much larger $R^{2}$ values $(>0.6)$ for the Gaotai and Zhangye stations, implying a relatively better simulation effect of precipitation. However, the downstream area is characterized by the vast Gobi desert, where the runoff is greatly reduced or disappears through evaporation and river leakage [31]. Some studies have shown the increasingly apparent phenomenon that climate change modeling in arid zones is extremely uncertain because of the extreme natural variability (both temporal and spatial) of the desert climate [53]. Meanwhile, given the low precipitation frequency in arid areas, the amount of useful data for the establishment of linear regression equations between predictands and predictors is limited. Nevertheless, in this study, the $R^{2}$ values of almost all of the stations surrounding the whole Heihe River basin were still larger than 0.5. The RMSE of each station was within $20 \%$ of the measured precipitation, which was considered acceptable. The NSE of each station during the calibration period and validation period were $0.333-0.838$ and $0.450-0.873$, respectively. The NSEs of all stations were all above 0.55 with the exception of the Ejin Banner, Jikede, and Guaizihu stations in the lower reaches for the reasons demonstrated above. To sum up, the overall effect achieved by the SDSM in simulating precipitation and temperature was acceptable. Future precipitation scenarios can be projected using the SDSM in the Heihe River basin.

Table 4. Deterministic coefficients of the statistical downscaling model (SDSM) during calibration and validation periods.

\begin{tabular}{ccccccccc}
\hline \multirow{2}{*}{ Stations } & \multicolumn{2}{c}{$\mathbf{T}_{\max }$} & \multicolumn{2}{c}{$\mathbf{T}_{\min }$} & \multicolumn{2}{c}{$\mathbf{T}_{\min }$} & \multicolumn{2}{c}{ Precipitation } \\
\cline { 2 - 8 } & Calibration & Validation & Calibration & Validation & Calibration & Validation & Calibration & Validation \\
\hline Ejin & 0.985 & 0.989 & 0.952 & 0.959 & 0.983 & 0.987 & 0.379 \\
Banner & 0.981 & 0.987 & 0.938 & 0.953 & 0.978 & 0.984 & 0.355 \\
Jikede & 0.972 & 0.984 & 0.933 & 0.939 & 0.980 & 0.982 & 0.449 \\
Guaizihu & \multicolumn{2}{c}{} & & & & & 0.535 \\
\hline
\end{tabular}


Table 4. Cont.

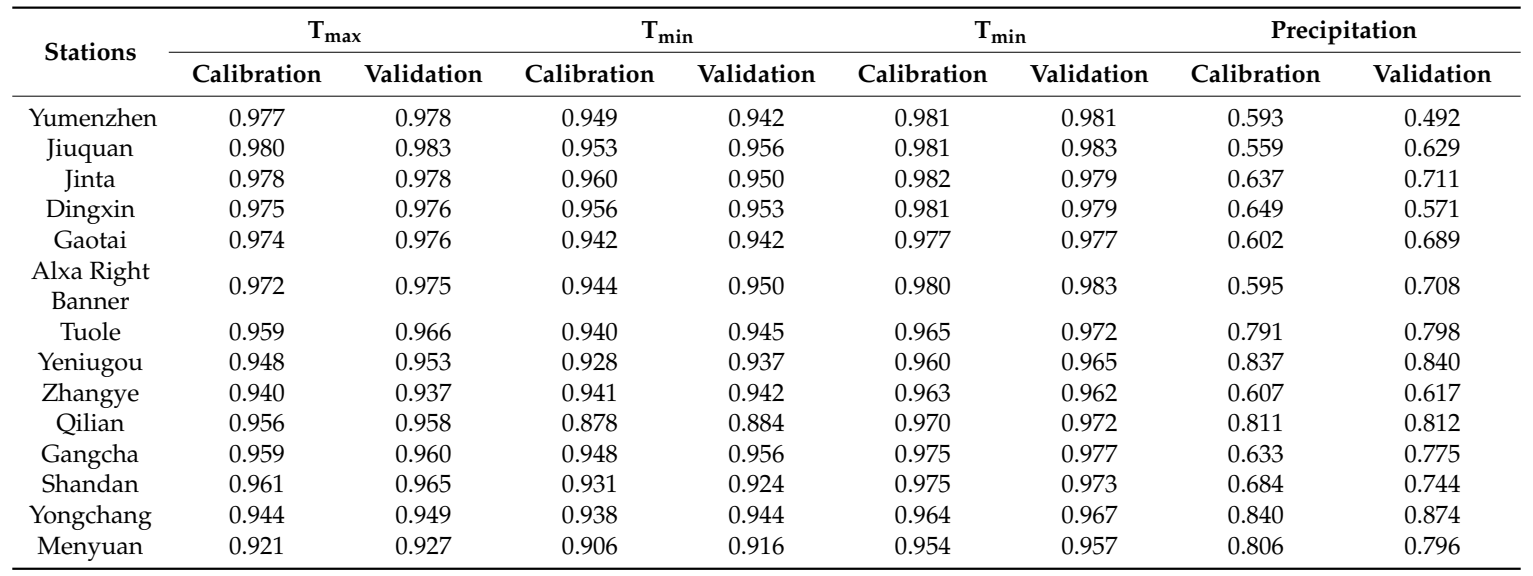

Table 5. Root mean square error (RMSE) results of the SDSM during calibration and validation periods.

\begin{tabular}{|c|c|c|c|c|c|c|c|c|}
\hline Stations & \multicolumn{2}{|c|}{ Tmax } & \multicolumn{2}{|c|}{ Tmin } & \multicolumn{2}{|c|}{ Tmin } & \multicolumn{2}{|c|}{ Precipitation } \\
\hline Ejin Banner & 1.755 & 1.474 & 3.013 & 2.764 & 1.841 & 1.607 & 4.807 & 4.053 \\
\hline Guaizihu & 2.388 & 1.797 & 3.540 & 3.504 & 1.991 & 1.920 & 5.473 & 5.509 \\
\hline Yumenzhen & 1.829 & 1.818 & 2.492 & 2.614 & 1.633 & 1.654 & 5.579 & 5.294 \\
\hline Jiuquan & 1.802 & 1.587 & 2.566 & 2.435 & 1.689 & 1.585 & 5.113 & 4.984 \\
\hline Gaotai & 1.933 & 1.816 & 2.637 & 2.561 & 1.762 & 1.725 & 8.483 & 6.811 \\
\hline $\begin{array}{l}\text { Alxa Right } \\
\text { Banner }\end{array}$ & 2.061 & 1.891 & 2.874 & 2.752 & 1.711 & 1.588 & 9.348 & 7.674 \\
\hline Tuole & 1.903 & 1.790 & 2.760 & 2.662 & 1.953 & 1.773 & 14.057 & 14.814 \\
\hline Yeniugou & 1.987 & 1.921 & 2.975 & 2.789 & 1.974 & 1.860 & 16.776 & 16.742 \\
\hline Zhangye & 2.820 & 2.908 & 2.722 & 2.689 & 2.221 & 2.259 & 9.161 & 8.380 \\
\hline Menyuan & 2.393 & 2.401 & 3.138 & 3.031 & 2.011 & 1.965 & 19.728 & 19.627 \\
\hline
\end{tabular}

Table 6. Nash-Sutcliffe efficiency coefficient (NSE) results of the SDSM during calibration and validation periods.

\begin{tabular}{|c|c|c|c|c|c|c|c|c|}
\hline \multirow{2}{*}{ Stations } & \multicolumn{2}{|c|}{ Tmax } & \multicolumn{2}{|c|}{ Tmin } & \multicolumn{2}{|c|}{ Tmin } & \multicolumn{2}{|c|}{ Precipitation } \\
\hline & Calibration & Valitation & Calibration & Valitation & Calibration & Valitation & Calibration & Valitation \\
\hline Ejin Banner & 0.985 & 0.988 & 0.952 & 0.955 & 0.983 & 0.986 & 0.333 & 0.623 \\
\hline Guaizihu & 0.972 & 0.983 & 0.933 & 0.932 & 0.980 & 0.981 & 0.411 & 0.450 \\
\hline Yumenzhen & 0.977 & 0.977 & 0.949 & 0.942 & 0.981 & 0.980 & 0.592 & 0.487 \\
\hline Jiuquan & 0.980 & 0.983 & 0.953 & 0.955 & 0.981 & 0.982 & 0.555 & 0.628 \\
\hline Gaotai & 0.974 & 0.975 & 0.942 & 0.942 & 0.977 & 0.976 & 0.584 & 0.676 \\
\hline $\begin{array}{l}\text { Alxa Right } \\
\text { Banner }\end{array}$ & 0.972 & 0.975 & 0.944 & 0.946 & 0.980 & 0.982 & 0.593 & 0.707 \\
\hline Tuole & 0.959 & 0.963 & 0.940 & 0.945 & 0.965 & 0.971 & 0.780 & 0.788 \\
\hline Yeniugou & 0.948 & 0.951 & 0.928 & 0.936 & 0.960 & 0.964 & 0.824 & 0.825 \\
\hline Zhangye & 0.940 & 0.933 & 0.941 & 0.941 & 0.963 & 0.961 & 0.572 & 0.614 \\
\hline Menyuan & 0.921 & 0.925 & 0.906 & 0.910 & 0.954 & 0.956 & 0.799 & 0.779 \\
\hline
\end{tabular}




\subsubsection{Future Precipitation Scenarios}

Based on the constructed SDSM, the selected top five GCMs were used to project the precipitation scenarios for the baseline period (1976-2005) and future period (2018-2047) in three RCP scenarios (RCP2.6, RCP4.5, and RCP8.5) for 17 meteorological stations surrounding the Heihe River basin. Changes in precipitation between the baseline period and future period were calculated to analyze the variation characteristics, which were both generated by GCM outputs, efficiently eliminating the systematic error of the GCMs [54]. As shown in Figure 4a, projected changes in future mean annual precipitation in the Heihe River basin varied at different meteorological stations. The CNRM-CM5 model, which showed the best performance in precipitation assessment, indicated a decreasing trend in the next 30 years compared with the baseline period in all three RCP scenarios, with a reduction within $-20 \%$. Changes in precipitation projected by the other four GCMs at the same meteorological stations in different RCP scenarios showed similar patterns, the amplifications of which were mostly within $\pm 10 \%$. Consistent with adaptive assessment results of GCMs, the CANESM2 model that got the lowest rank score value of the precipitation among the selected GCMs projected the greatest variation range, from +32.4 to $-41.2 \%$.

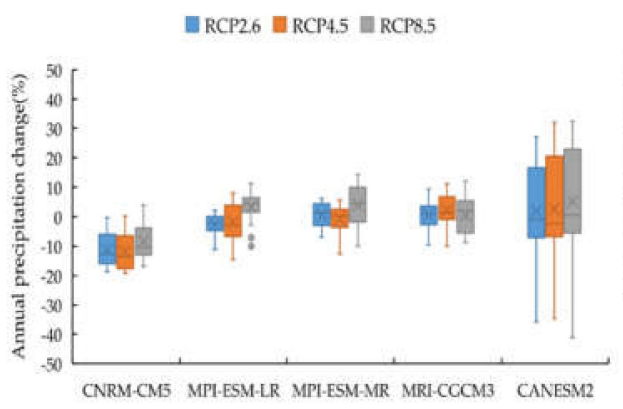

(a)

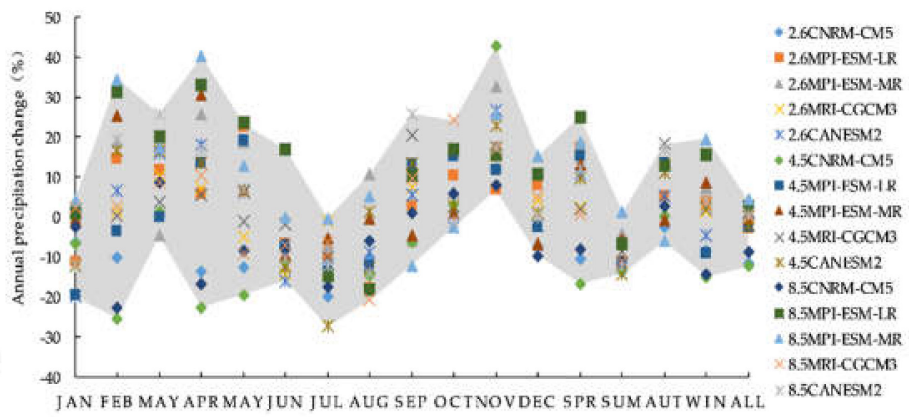

(b)

Figure 4. Multi-model projected changes in mean annual precipitation (a) in different Representative Concentration Pathway (RCP) scenarios and (b) at different time scales in the Heihe River basin.

The monthly, seasonal, and annual variation ranges of precipitation projected by multi-GCMs in the three RCP scenarios are shown in Figure $4 \mathrm{~b}$. The changes in future precipitation in the Heihe River basin in different scenarios varied significantly from -28 to $43 \%$ at different time scales. The summer precipitation in most scenarios showed a downward trend with a maximum decline of $-14.2 \%$, while simulated results of spring precipitation by all GCMs showed an upward trend with a maximum increase of $25.1 \%$, except for the CNRM-CM5 model. The precipitation in July exhibited the greatest reduction $(-27.3 \%)$, while the greatest increase in precipitation occurred in November with a rate of $42.8 \%$.

Based on the interpolation of the mean annual precipitation from the 17 meteorological stations to the whole basin during the baseline period and the future period, spatial variations in precipitation in the upper, middle, and lower reaches of the Heihe River basin were obtained in the RCP2.6, RCP4.5, and RCP8.5 scenarios, respectively. As shown in Figure 5, the mean annual precipitation scenarios projected by the CNRM-CM5 presented a consistent downward trend in the upper, middle, and lower reaches, and the reduction of precipitation gradually decreased from upstream to downstream. In the upper reaches, the projected precipitation scenarios of the other four GCMs mostly showed a downward trend with a maximum decline of $-11.9 \%$, except for MRI-CGCM3. In the middle reaches, only the precipitation projected by CANESM2 and CNRM-CM5 showed a downward trend, while the projected precipitation of the other three GCMs showed an upward trend, and the overall variation ranged from -11.4 to $6.9 \%$. The variation in projected precipitation in the lower reaches was much more dramatic than that in the upper and middle reaches, with the changing range between -34.9 and $11.3 \%$. Significant differences in projected precipitation by different GCMs were also screened in lower reaches; the simulated precipitation results of CANESM2 and MPI-ESM-MR showed 
an increasing trend, while the other three GCMs (CNRM-CM5, MPI-ESM-LR and MRI-CGCM3) indicated a decreasing trend.

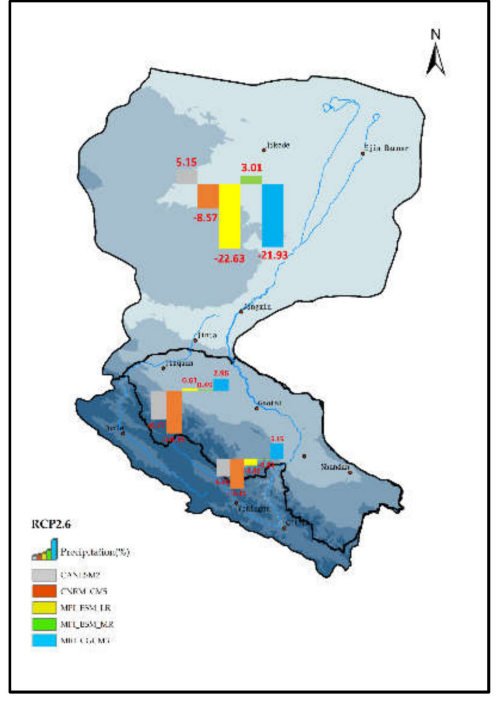

(a)

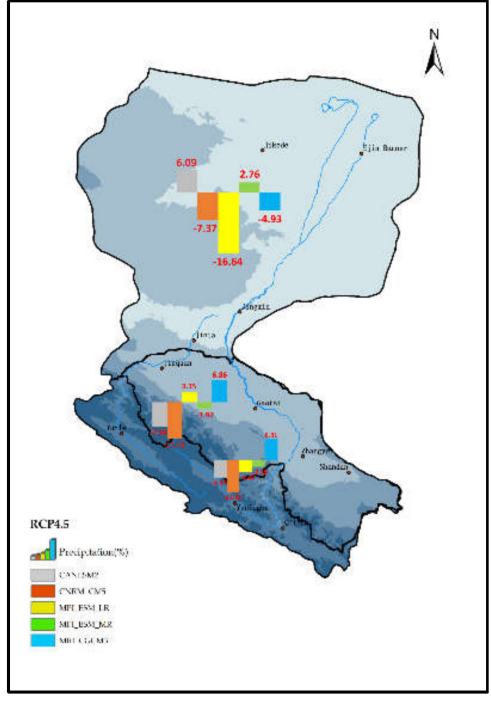

(b)

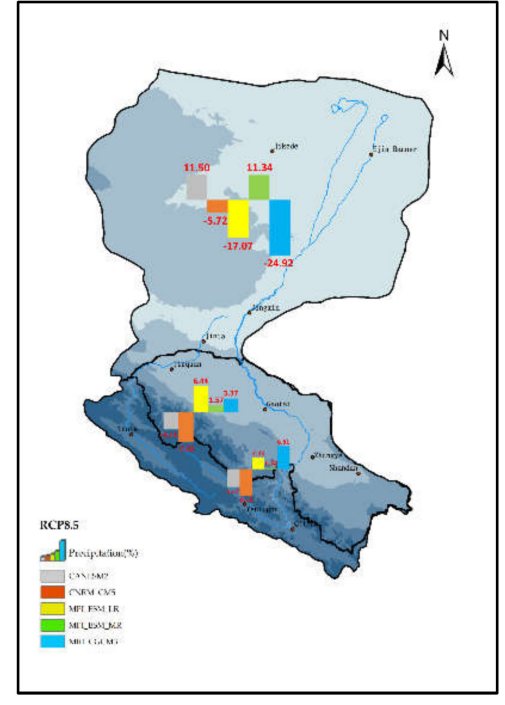

(c)

Figure 5. Multi-model projected spatial variations in mean annual precipitation: (a) RCP2.6; (b) RCP4.5; (c) RCP8.5.

\subsubsection{Future Maximum Air Temperature Scenarios}

The mean annual maximum air temperature changes of each meteorological station simulated by multi-models in the three scenarios in the basin are shown in Figure 6a. It can be clearly seen that the maximum air temperature simulated by all GCMs in different scenarios showed an upward trend over the next 30 years. Results simulated by most GCMs showed similar temperature amplifications as follows: RCP8.5 > RCP4.5 > RCP2.6, i.e., the temperature amplification was greater as concentration of $\mathrm{CO}_{2}$ increased. Variations in the maximum air temperature in the 17 meteorological stations generated by the MRI-CGCM3 model showed the smallest range between 0.5 and $1.3^{\circ} \mathrm{C}$, while variations in the maximum air temperature generated by the CANESM2 model indicated the largest range between 1.7 and $2.5^{\circ} \mathrm{C}$ in most stations. Variations in the maximum air temperature simulated by other GCMs ranged between 0.8 and $2.0^{\circ} \mathrm{C}$.

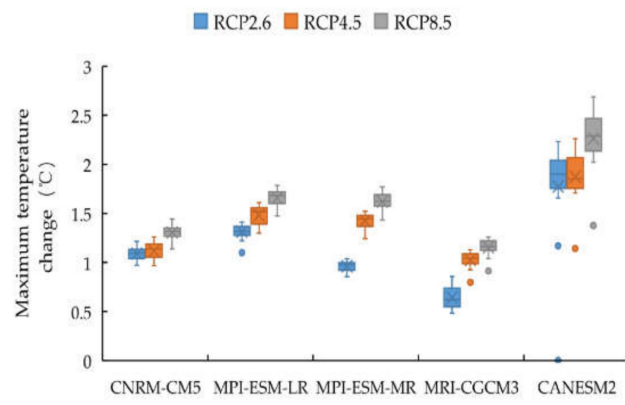

(a)

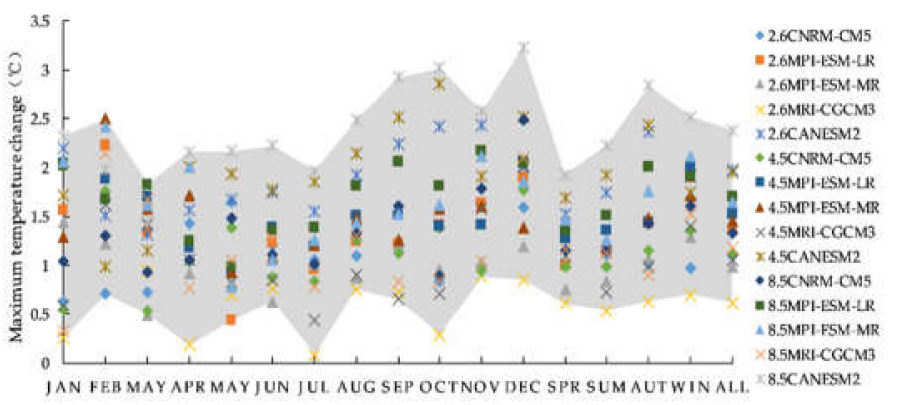

(b)

Figure 6. Multi-model projected change in mean maximum air temperature: (a) in different RCP scenarios; (b) at different time scales in the Heihe River basin.

The monthly, seasonal, and annual variation ranges of the maximum air temperature projected by multi-GCMs in the three RCP scenarios are shown in Figure 6b. The maximum air temperature simulated by different GCMs also exhibited an increasing trend in all the three RCP scenarios at 
different time scales, and this is consistent with the above analysis. The maximum air temperature simulated by the CANESM model in the RCP8.5 scenario mostly contributed to the upper limit values of the variation ranges at different time scales, while simulations of the MRI-CGCM3 model in the RCP2.6 scenario accounted for the lower limit values of the variation ranges. Monthly and seasonal changes also showed significant differences among multi-models in the three scenarios. Compared with the baseline period, the increase in the maximum air temperature in December was the most obvious, with a maximum amplification of $3.2^{\circ} \mathrm{C}$. The increase in autumn was the most obvious with a maximum amplification of $2.8^{\circ} \mathrm{C}$, while the increase in spring showed a relatively smaller variation range than other seasons. Most of the remaining monthly and seasonal maximum air temperatures increased between 0.5 and $2.0^{\circ} \mathrm{C}$.

Spatial variations in the maximum air temperature in the upper, middle, and lower reaches in the Heihe River basin simulated by multi-GCMs in different scenarios are shown in Figure 7. The projected scenarios of mean annual maximum air temperature by all GCMs in the three RCP scenarios implied a consistent warming trend in the whole basin, and the increasing rates gradually amplified as the $\mathrm{CO}_{2}$ emission concentration increased. However, increasing rates in different regions exhibited significant differences. The maximum air temperature projected by the CANESM model in the upper reaches in the RCP8.5 scenario was the most amplified $\left(+2.4^{\circ} \mathrm{C}\right)$, while the projected minimum increase in the maximum air temperature occurred in the lower reaches, which was simulated by the MRI-CGCM3 model in the RCP2.6 scenario $\left(+0.5^{\circ} \mathrm{C}\right)$. Compared with the increases in the lower reaches, the increases in the upper reaches projected in the three scenarios were slightly larger.

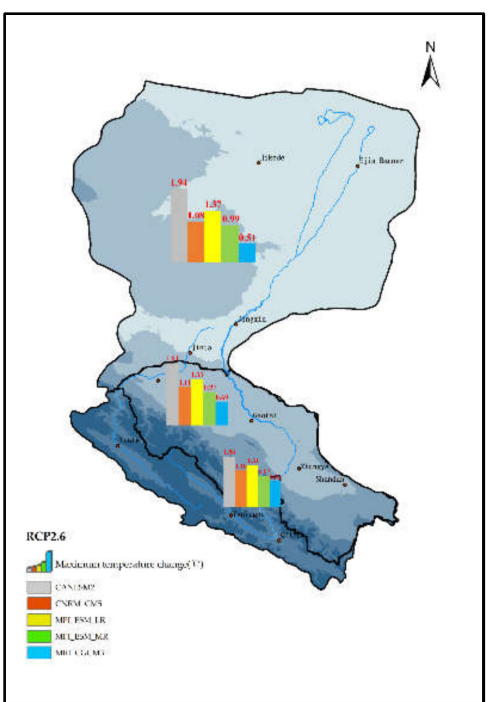

(a)

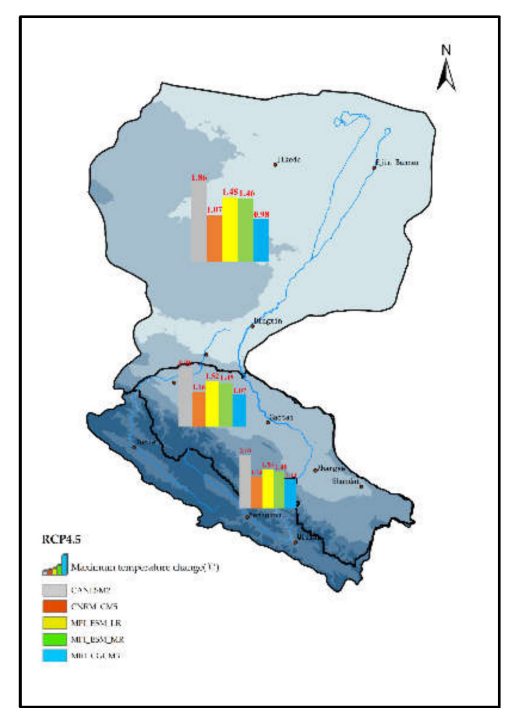

(b)

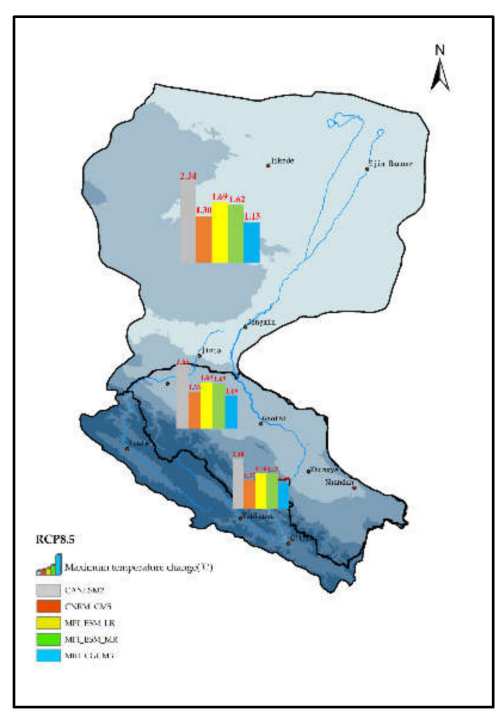

(c)

Figure 7. Multi-model projected spatial variations in maximum air temperature in (a) RCP2.6; (b) RCP4.5; (c) RCP8.5.

\subsubsection{Future Minimum Air Temperature Scenarios}

The mean annual minimum air temperature changes of each meteorological station simulated by multi-models in the three scenarios in the Heihe River basin are shown in Figure 8a. Similar to the increasing trend of the maximum air temperature, the projected minimum air temperature showed an upward trend in different scenarios, which increased corresponding to the elevated $\mathrm{CO}_{2}$ concentration. Furthermore, the greatest amplifications were also simulated by the CANESM2 model in all three RCP scenarios $\left(1.3-2.3^{\circ} \mathrm{C}\right)$, while lower increases simulated by the other GCMs ranged from 0.5 to $1.5^{\circ} \mathrm{C}$. 

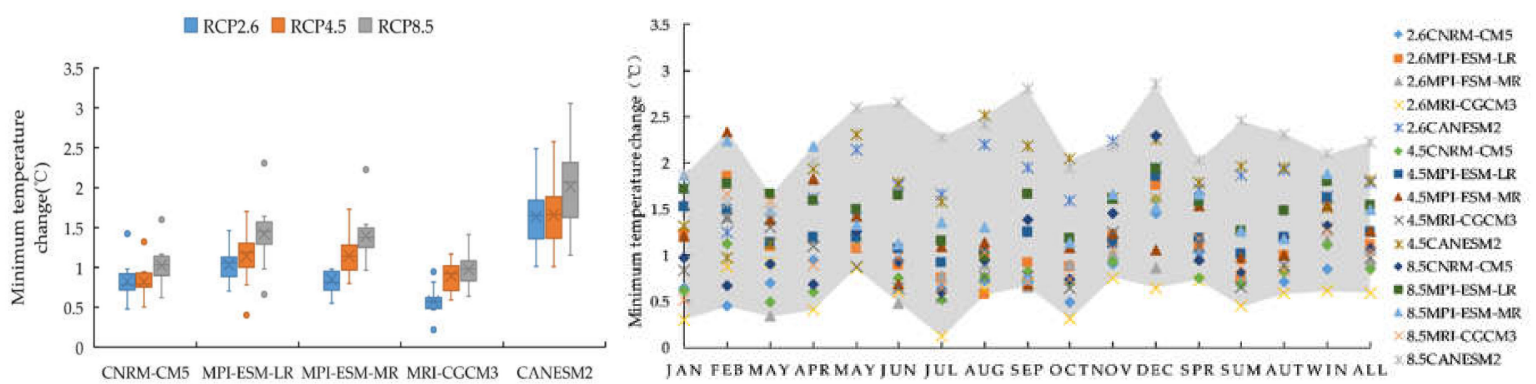

Figure 8. Multi-model projected change in mean maximum air temperature (a) in different RCP scenarios and (b) at different time scales in the Heihe River basin.

Figure $8 \mathbf{b}$ shows the spatial variations in the projected minimum air temperature at monthly, seasonal and annual scales. The minimum air temperature simulated by different GCMs also exhibited an increasing trend in all the three RCP scenarios at different time scales, which were consistent with the temporal variations in the maximum air temperature. The minimum air temperature simulated by the CANESM model in the RCP8.5 scenario mostly contributed to the upper limit values of the variation ranges at different time scales, while simulations of the MRI-CGCM3 model in the RCP2.6 scenario accounted for the lower limit values of the variation ranges. As to monthly variations, the minimum air temperature increased the most in May, June, September and December amplifying over $2.5^{\circ} \mathrm{C}$. And the projected largest increase in the seasonal minimum air temperature occurred in summer, with the highest amplification of $2.5^{\circ} \mathrm{C}$. Different from variations in the maximum air temperature, increases of the minimum air temperature in most scenarios were much more densely concentrated between 0.5 and $1.5^{\circ} \mathrm{C}$ at different time scales, which were lower than increases of the maximum air temperature.

Spatial variations in the minimum air temperature in the upper, middle and lower reaches in the Heihe River basin simulated by multi-GCMs in different scenarios are shown in Figure 9. The projected scenarios of mean annual minimum air temperature by all GCMs in the three RCP scenarios, similar to the maximum air temperature, implied a consistent warming trend in the whole basin, and the increasing rates gradually amplified as the $\mathrm{CO}_{2}$ emission concentration increased. However, the increasing rates exhibited significant differences in different reaches. The minimum air temperature projected by the CANESM model in the upper reaches in the RCP8.5 scenario was the most amplified $\left(+2.2^{\circ} \mathrm{C}\right)$, while the projected minimum increase occurred in the lower reaches, which was simulated by the MRI-CGCM3 model in the RCP2.6 scenario $\left(+0.5^{\circ} \mathrm{C}\right)$. Although increases of both maximum and minimum air temperature in the upper reaches projected in the three scenarios were larger than those in the middle and lower reaches, the amplifications of the minimum air temperature were much more significant compared with those of the maximum air temperature. 


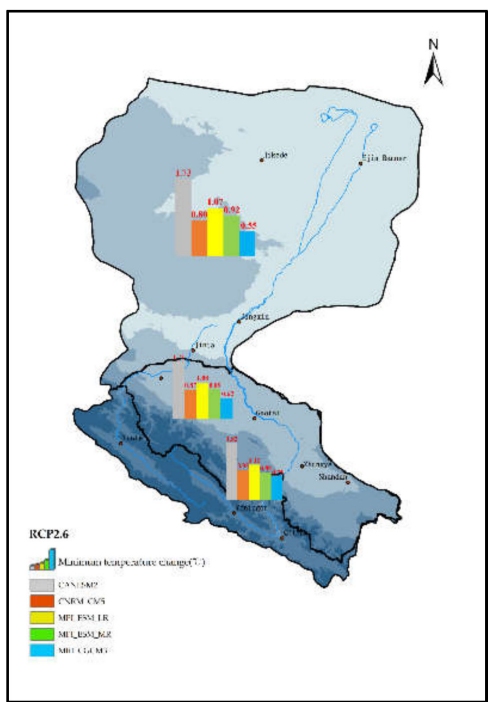

(a)

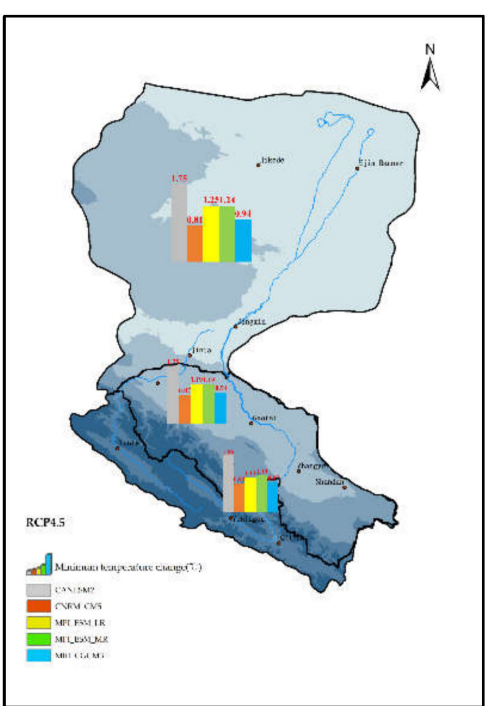

(b)

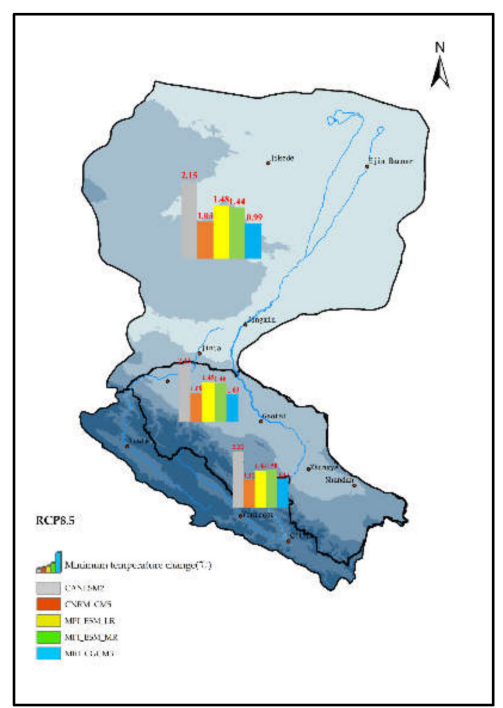

(c)

Figure 9. Multi-model projected spatial variations in minimum air temperature in (a) RCP2.6; (b) RCP4.5; (c) RCP8.5.

\section{Conclusions}

In this study, a statistical downscaling model (SDSM) was constructed based on observed data from 17 meteorological stations, 23 GCM data, and ERA-40 data in the Heihe River basin, which projected future climate change scenarios by multi-models under three RCP scenarios. The main conclusions are as follows:

(1) Among the 23 GCMs selected from CMIP5 using for performance evaluation in the Heihe River basin, precipitation was best represented by CNRM-CM5, MPI-ESM-LR, and MPI-ESM-MR. Maximum air temperature was best simulated by MPI-ESM-LR, IPSL-CM5A-LR, and BCC-CSM-1-1-M, while minimum air temperature was best simulated by BCC-CSM1-1-M, MPI-ESM-MR, and GISS-E2-R. The sensitivity analysis for climate variables implied that the GCMs' adaptive assessment results were influenced significantly by climate variables, and precipitation was the most sensitive variable.

(2) The SDSM has better effects in terms of temperature simulation for the Heihe River basin. However, the $R^{2}$ values of precipitation during the calibration period and validation period, compared with those of air temperature, were slightly lower and were still larger than 0.5 at most stations. The RMSE of each station was within $20 \%$ of the measured precipitation, and this was considered acceptable. The NSE values of each station during the calibration period and validation period were $0.333-0.838$ and $0.450-0.873$, respectively. These statistical parameters meet the accuracy requirements, but they also indicate that it is difficult to predict future precipitation more accurately than temperature. In view of this conclusion, the reasons are summarized as follows: (i) Because the precipitation of the Heihe River basin is not only affected by atmospheric circulation factors but also by underlying surface conditions and human activities, it is difficult to accurately capture characteristics of precipitation. (ii) The inland arid region of Northwest China is an area that, on a global scale, responds most sensitively to global climate change, and the downstream area of this region is mostly covered by the Gobi desert, which has low precipitation frequency and is highly unpredictable because of the extreme natural variability.

(3) Projected changes in future mean annual precipitation in the Heihe River basin varied among meteorological stations, which indicates a dramatic decreasing trend over the next 30 years compared with the baseline period in the three RCP scenarios (RCP2.6, RCP4.5, and RCP8.5). The changes in future precipitation in the Heihe River basin in the different scenarios varied significantly with seasonal changes at different time scales. The summer precipitation in most scenarios showed a downward trend, while the projected spring precipitation by all GCMs showed an upward trend 
except CNRM-CM5. The spatial variations in precipitation in the upper, middle, and lower reaches of the Heihe River basin were obtained in the three scenarios, and a downward trend in projected precipitation was shown by most GCMs in the upper reaches, with a maximum decline of $11.92 \%$. In the middle reaches, projected precipitation by most GCMs showed a downward trend, and the variation ranged from -11.4 to $6.9 \%$. Due to the extremely natural variability in the downstream area covered mainly by the Gobi desert and the relatively lower model performance, variations in the projected precipitation in the lower reaches were much more dramatic than those in the upper and middle reaches, with the changing range between -24.9 and $11.3 \%$.

(4) The maximum air temperature and minimum air temperature simulated by all GCMs in all scenarios (RCP2.6, RCP4.5, RCP8.5) showed an upward trend for the next 30 years. Results simulated by most GCMs exhibited an increasing air temperature due to the amplification of typical concentration targets, i.e., air temperature amplification was greater as concentration of $\mathrm{CO}_{2}$ increased in the same model. Meanwhile, compared with the minimum air temperature, the increase range of the maximum air temperature in all scenarios was greater. Compared with the increases in the lower reaches, the increases in the upper reaches projected in multiple scenarios were slightly larger. The maximum air temperature simulated by different GCMs also exhibited an increasing trend in all the three RCP scenarios at different time scales, and the increase in autumn was the most obvious with a maximum amplification of $2.8^{\circ} \mathrm{C}$. In contrast, the projected largest increase in the seasonal minimum air temperature occurred in summer, with the highest amplification of $2.5^{\circ} \mathrm{C}$.

In this study, the top 5 GCMs were selected by rank score to use the SDSM to project future climate change in the RCP2.6, RCP4.5 and RCP8.5 scenarios in the inland arid regions of Northwest China. The results could provide scientific reference for sustainable agricultural production and water resources management in arid inland areas subject to climate change. However, there are too many uncertainties in projected extreme events to obtain accurate results, especially climate events that are precipitation-related. Such uncertainties pertain to events, the influence of predictors, the underlying surface conditions of the simulated area, and human activities. Therefore, further research is still needed.

Author Contributions: Conceptualization, L.L.; methodology, L.L., C.Y., and R.W.; data curation, Q.C.; validation, R.W., Q.C., and C.Y.; formal analysis, R.W. and C.Y.; investigation, R.W. and Q.C.; resources, L.L.; writing-original draft preparation, R.W. and C.Y; writing-review and editing, L.L. and G.H.; visualization, R.W. and L.L; supervision, L.L.; funding acquisition, L.L. and G.H.

Funding: This research was financially supported by the National Key R\&D Program of China (No. 2017YFC0403201) and the National Natural Science Foundation of China (No. 91425302).

Acknowledgments: Meteorological data and ERA-40 reanalysis data were supplied by China Meteorological Data Service Center (http:/ / data.cma.cn/) and the European Center for Medium-Range Weather Forecasts (http://apps.ecmwf.int/datasets/data/era40-daily/levtype=sfc/). The authors are also grateful to the World Climate Research Programme's Working Group on Coupled Modelling, which is responsible for CMIP, and to the climate modeling groups (listed in Table 1 of this paper) for producing and making available their model output (http://cmip-pcmdi.llnl.gov/cmip5/).

Conflicts of Interest: The authors declare no conflict of interest.

\section{References}

1. Ma, Y.; Liu, H.Z.; Jin, L. Development and research progress for regional climate model. Gansu Sci. Technol. 2006, 22, 137-139. (In Chinese)

2. Ministry of Water Resources of the People's Republic of China. Recent Management Plan for the Heihe River Basin; China Water Conservancy and Hydropower Press: Beijing, China, 2001. (In Chinese)

3. Zhao, C.Y.; Nan, Z.R.; Cheng, G.D.; Zou, S.B.; Zhang, Y.Z. Prediction of the trend of the future climate change in Northwestern China by statistical downscaling. J. Lanzhou Univ. 2008, 44, 12-25. (In Chinese)

4. Chen, Y.N.; Li, Z.; Fan, Y.T.; Wang, H.J.; Deng, H.J. Progress and prospect prospects of climate change impacts on hydrology in the arid region of northwest China. Environ. Res. 2005, 139, 11-19. [CrossRef] [PubMed] 
5. Chen, Y.N.; Yang, Q.; Luo, Y.; Shen, Y.J.; Pan, X.L.; Li, L.H.; Li, Z.Q. Ponder on the issue of water resources in the arid region of northwest China. Arid Land Geogr. 2012, 35, 1-9. (In Chinese)

6. Wang, H.J.; Chen, Y.N.; Chen, Z.S. Spatial distribution and temporal trends of mean precipitation and extremes in the arid region, northwest of China, during 1960-2010. Hydrol. Process. 2013, 27, 1807-1818. [CrossRef]

7. Shang, S.S.; Lian, L.S.; Ma, T.; Han, T. Spatiotemporal variation of temperature and precipitation in northwest China in recent 54 years. Arid Zone Res. 2018, 35, 68-76. (In Chinese)

8. Xiao, G.J.; Zhang, Q.; Li, Y.; Wang, R.Y.; Yao, Y.B.; Zhao, H.; Bai, H.Z. Impact of temperature increase on the yield of winter wheat at low and high altitudes in semiarid northwestern China. Agric. Water. Manag. 2010, 97, 1360-1364. [CrossRef]

9. Wang, H.J.; Chen, Y.N.; Li, W.H. Hydrological extreme variability in the headwater of Tarim River: Links with atmospheric teleconnection and regional climate. Stoch. Environ. Res. Risk. Assess. 2014, 28, 443-453. [CrossRef]

10. Zhao, Y.F.; Zhang, B.; Zhang, Y.N.; Wang, Q.; He, X.Q.; Yin, H.X. Impacts of climate change on agriculture production in the Heihe river basin in recent 50 years. J. Arid Land Res. Environ. 2012, 26, 130-136. (In Chinese)

11. Wang, Y.H.; Li, Z.L.; Zhao, W. Non-stationary frequency analysis of extreme high temperature in the Heihe River Basin. Geogr. Res. 2017, 36, 755-764. (In Chinese)

12. Foley, A.; Kelman, I. EURO-CORDEX regional climate model simulation of precipitation on Scottish islands (1971-2000): Model performance and implications for decision-making in topographically complex regions. Int. J. Climatol. 2018, 38, 1087-1095. [CrossRef]

13. Gao, X.J.; Wang, M.L.; Giorgi, F. Climate change over China in the 21st century as simulated by BCC_CSM1.1-RegCM4.0. Atmos Ocean. Sci. Lett. 2013, 6, 381-386.

14. Wang, X.Y.; Yang, T.; Shao, Q.X.; Acharya, K.; Wang, W.G.; Yu, Z.B. Statistical downscaling of extremes of precipitation and temperature and construction of their future scenarios in an elevated and cold zone. Stoch. Environ. Res. Risk. Assess. 2012, 26, 405-418. [CrossRef]

15. Khalili, M.; Van Nguyen, V.T. An efficient statistical approach to multi-site downscaling of daily precipitation series in the context of climate change. Clim. Dyn. 2017, 49, 2261-2278. [CrossRef]

16. Wilby, R.L.; Dawson, C.W.; Barrow, E.M. SDSM-A decision support tool for the assessment of regional climate change impacts. Environ. Modell. Softw. 2002, 17, 145-157. [CrossRef]

17. Stennett-Brown, R.K.; Jones, J.J.P.; Stephenson, T.S.; Taylor, M.A. Future Caribbean temperature and rainfall extremes from statistical downscaling. Int. J. Climatol. 2017, 37, 4828-4845. [CrossRef]

18. Tang, J.P.; Niu, X.R.; Wang, S.Y.; Gao, H.X.; Wang, X.Y.; Wu, J. Statistical downscaling and dynamical downscaling of regional climate in China: Present climate evaluations and future climate projections. J. Geophys. Res.-Atmos. 2016, 121, 2110-2129. [CrossRef]

19. Gulacha, M.M.; Mulungu, D.M.M. Generation of climate change scenarios for precipitation and temperature at local scales using SDSM in Wami-Ruvu River Basin Tanzania. Phys. Chem. Earth Parts A/B/C 2017, 100, 62-72. [CrossRef]

20. Hoan, N.X.; Khoi, D.N.; Nhi, P.T.T. Uncertainty assessment of streamflow projection under the impact of climate change in the Lower Mekong Basin: A case study of the Srepok River Basin, Vietnam. Water Environ. J. 2018, 32, 1-12. [CrossRef]

21. Hassan, Z.; Shamsudin, S.; Harun, S. Application of SDSM and LARS-WG for simulating and downscaling of rainfall and temperature. Theor. Appl Climatol. 2014, 116, 243-257. [CrossRef]

22. Badou, D.F.; Diekkrüger, B.; Kapangaziwiri, E.; Mbaye, M.L.; Yira, Y.; Lawin, E.A.; Oyerinde, G.T.; Afouda, A. Modelling blue and green water availability under climate change in the Beninese Basin of the Niger River Basin, West Africa. Hydrol. Process. 2018, 32, 2526-2542. [CrossRef]

23. Chen, J.; Brissette, F.P.; Annie, P.; Leconte, R. Overall uncertainty study of the hydrological impacts of climate change for a Canadian watershed. Water. Resour. Res. 2011, 47, 1-16. [CrossRef]

24. Elguindi, N.; Grundstein, A.; Feddema, J.J. Assessment of CMIP5 global model simulations and climate change projections for the 21 st century using a modified Thornthwaite climate classification. Clim. Chang. 2014, 122, 523-538. [CrossRef]

25. Shi, Y.; Gao, X.J.; Zhang, D.F.; Giorgi, F. Climate change over the Yarlung Zangbo-Brahmaputra River Basin in the 21st century as simulated by a high resolution regional climate model. Quatern. Int. 2011, 244, 159-168. [CrossRef] 
26. Dessai, S.; Hulme, M. Assessing the robustness of adaptation decisions to climate change uncertainties: A case study on water resources management in the East of England. Glob. Environ. Chang. 2007, 17, 59-72. [CrossRef]

27. Fu, G.B.; Liu, Z.F.; Charles, S.P.; Xu, Z.X.; Yao, Z.Y. A score-based method for assessing the performance of GCMs: A case study of southeastern Australia. J. Geophys. Res.-Atmos. 2013, 118, 4154-4167. [CrossRef]

28. Zhang, L.; Nan, Z.T.; Yu, W.J.; Ge, Y.C. Modeling Land-Use and Land-Cover Change and Hydrological Responses under Consistent Climate Change Scenarios in the Heihe River Basin, China. Water. Resour. Manag. 2015, 29, 4701-4717. [CrossRef]

29. Zang, C.F.; Liu, J.G. Spatial and temporal pattern difference of blue-green water flows in typical reference years in the Heihe river basin, northwestern China. J. Beijing Forest. Univ. 2013, 35, 1-10. (In Chinese)

30. Wu, F.; Zhan, J.Y.; Wang, Z.; Zhang, Q. Streamflow variation due to glacier melting and climate change in upstream Heihe River Basin, Northwest China. Phys. Chem. Earth. 2015, 79-82, 11-19. [CrossRef]

31. Zhang, A.J.; Zheng, C.M.; Yao, Y.Y. Analysis of streamflow variations in the Heihe River Basin, northwest China: Trends, abrupt changes, driving factors and ecological influences. J. Hydrol. Reg. Study 2015, 3, 106-124. [CrossRef]

32. Bao, X.H.; Zhang, F.Q. Evaluation of NCEP-CFSR, NCEP-NCAR, ERA-Interim, and ERA-40 reanalysis datasets against independent sounding observations over the Tibetan Plateau. J. Clim. 2013, 26, 206-214. [CrossRef]

33. Frauenfeld, O.W.; Zhang, T.J.; Serreze, M.C. Climate change and variability using European Centre for Medium-Range Weather Forecasts reanalysis (ERA-40) temperatures on the Tibetan Plateau. J. Geophys. Res.-Atmos. 2005, 110, D02101. [CrossRef]

34. Hu, L.S.; Huang, G.; Hu, K.M. The performance of multiple datasets in characterizing the changes of extreme air temperature over China during 1979 to 2012. Theor. Appl. Climatol. 2018, 133, 619-632. [CrossRef]

35. Van Vuuren, D.P.; Edmonds, J.; Kainuma, M.; Riahi, K.; Thomson, A.; Hibbard, K.; Hurtt, G.C.; Kram, T.; Krey, V.; Lamarque, J.F.; et al. The representative concentration pathways: An overview. Clim. Chang. 2011, 109, 5-31. [CrossRef]

36. Johnson, F.; Sharma, A. A nesting model for bias correction of variability at multiple time scales in general circulation model precipitation simulations. Water. Resour. Res. 2012, 48, W01504. [CrossRef]

37. Rosenberg, E.A.; Keys, P.W.; Booth, D.B.; Hartley, D.; Burkey, J.; Steinemann, A.C.; Lettenmaier, D.P. Precipitation extremes and the impacts of climate change on stormwater infrastructure in Washington State. Clim. Chang. 2010, 102, 319-349. [CrossRef]

38. Chen, J.; Chen, H.; Guo, S.L. Multi-site precipitation downscaling using a stochastic weather generator. Clim. Dyn. 2017, 50, 1975-1992. [CrossRef]

39. Kudo, R.; Yoshida, T.; Masumoto, T. Uncertainty analysis of impacts of climate change on snow processes: Case study of interactions of GCM uncertainty and an impact model. J. Hydrol. 2017, 548, 196-207. [CrossRef]

40. Vetter, T.; Reinhardt, J.; Floerke, M.; Van Griensven, A.; Hattermann, F.; Huang, S.C.; Koch, H.; Pechlivanidis, I.G.; Plötner, S.; Seidou, O.; et al. Evaluation of sources of uncertainty in projected hydrological changes under climate change in 12 large-scale river basins. Clim. Chang. 2017, 141, 419-433. [CrossRef]

41. Harvey, L.D.D.; Wigley, T.M.L. Characterizing and comparing control-run variability of eight coupled AOGCMs and of observations. Part 1: Temperature. Clim. Dyn. 2003, 21, 619-646. [CrossRef]

42. Nyeko-Ogiramoi, P.; Ngirane-Katashaya, G.; Willems, P.; Ntegeka, V. Evaluation and inter-comparison of Global Climate Models' performance over Katonga and Ruizi catchments in Lake Victoria basin. Phys. Chem. Earth 2010, 35, 618-633. [CrossRef]

43. Wilby, R.L.; Hay, L.E.; Leavesley, G.H. A comparison of downscaled and raw GCM output: Implications for climate change scenarios in the San Juan River basin, Colorado. J. Hydrol. 1999, 225, 67-91. [CrossRef]

44. Wilby, R.L.; Hassan, H.; Hanaki, K. Statistical downscaling of hydrometeorological variables using general circulation model output. J. Hydrol. 1998, 205, 1-19. [CrossRef]

45. Xu, Y.; Wang, S.J.; Bai, X.Y.; Li, X.Y.; Shi, X.M.; Tian, Y.C.; Wu, L.H. Simulation of future scenarios of climate change in the middle and upper reaches of the Peal River using the Statistical Down Scaling Model (SDSM). Carsol. Sin. 2018, 37, 228-237. (In Chinese)

46. Wilby, R.L.; Wigley, T.M.L. Precipitation predictors for downscaling: Observed and general circulation model relationships. Int. J. Climatol. 2000, 20, 641-661. [CrossRef] 
47. Hessami, M.; Gachon, P.; Ouarda, T.; St-Hilaire, A. Automated regression-based statistical downscaling tool. Environ. Modell. Softw. 2008, 23, 813-834. [CrossRef]

48. Guo, Z.Z. Evaluation of Water Productivity in Irrigated Areas of the Middle Heihe River Basin under Climate Change. Master's Thesis, China Agricultural University, Beijing, China, 2017. (In Chinese)

49. Cavazos, T.; Hewitson, B.C. Performance of NCEP-NCAR reanalysis variables in statistical downscaling of daily precipitation. Clim. Res. 2005, 28, 95-107.

50. Fan, L.J.; Fu, Z.B.; Chen, D.L. Review on creating future climate change scenarios by statistical downscaling techniques. Adv. Earth science. 2005, 20, 320-329. (In Chinese)

51. Qi, X.F.; L, W.P.; Li, H.T.; Liu, H.W. Future climate change prediction of arid inland river basin based on CMIP5 model. Arid Land Geogr. 2017, 40, 987-996. (In Chinese)

52. Hao, L.N.; Su, X.L.; Wang, N. Future spatial and temporal changes of temperature and precipitation in Hexi corridor based on SDSM. Nat. Sci. Ed. 2015, 43, 119-228. (In Chinese)

53. Lioubimtseva, E.; Cole, R. Uncertainties of climate change in arid environments of Central Asia. Rev. Fish. Sci. 2006, 14, 29-49. [CrossRef]

54. Liu, Z.F. Impacts of Climate Change on Main Hydrological Factors: In the Source Region of the Tarim River Basin. Ph.D. Thesis, Beijing Normal University, Beijing, China, 2010. (In Chinese)

(c) 2019 by the authors. Licensee MDPI, Basel, Switzerland. This article is an open access article distributed under the terms and conditions of the Creative Commons Attribution (CC BY) license (http://creativecommons.org/licenses/by/4.0/). 